\title{
A produção escrita de artigo no contexto acadêmico: as contribuições da abordagem Sistêmico-Funcional
}

\author{
Záira Bomfante dos Santos ${ }^{1}$ \\ Programa de Pós-Graduação em Ensino na Educação Básica, Universidade Federal do Espírito Santo, \\ São Mateus, ES, Brasil \\ Flaviane Faria Carvalho \\ Instituto de Ciências Humanas e Letras, Universidade Federal de Alfenas, Alfenas, MG, Brasil
}

Resumo: Este artigo investiga em que medida a abordagem linguística sistêmico-funcional, em interface com a sociorretórica, se aplica em textos produzidos pelas áreas de Humanidades e Ciências da Natureza e Matemática. O corpus de análise é composto por artigos acadêmicos produzidos por alunos afiliados a diferentes áreas do conhecimento matriculados em uma disciplina de pós-graduação com foco em letramento acadêmico. Os principais resultados obtidos demonstram que: a) a estratégia retórica mais expressiva nos artigos analisados é a citação de pesquisas prévias, buscando o respaldo de outros estudos relacionados com o tema investigado para desenvolverem suas próprias pesquisas; b) enquanto a área de Ciências Humanas parece valorizar a explicação dos objetivos, justificativa, relevância e escopo geral do trabalho, apontando para generalizações acerca dos resultados encontrados, as Ciências da Natureza e Matemática priorizam a avaliação das contribuições e implicações teóricas dos resultados encontrados na pesquisa para a área, bem como os impactos do estudo e aplicação dos seus resultados na realidade social.

Palavras-chave: Abordagem Sistêmico-Funcional; Sociorretórica; Gênero Acadêmico Artigo.

Title: The written production of article in the academic context: The contributions of the SystemFunctional Approach

Abstract: This article investigates to what extent the systemic-functional linguistic approach, in interface with the social rhetorical analysis, is applied in texts produced by the Humanities and Natural Sciences and Mathematics. The corpus of analysis is composed of academic articles produced by students affiliated to different areas of knowledge enrolled in a postgraduate discipline focusing on academic literacy. The main results obtained demonstrate that: a) the most expressive rhetorical strategy in the articles analyzed is the citation of previous research, seeking the support of other studies related to the topic investigated to develop their own research; b) while the Human Sciences area seems to value the explanation of the objectives, justification, relevance and general scope of the work, pointing to generalizations about the results found, the Nature Sciences and

\footnotetext{
${ }^{1}$ Doutora em Estudos Linguísticos pela Universidade Federal de Minas Gerais - UFMG. Professora da Universidade Federal do Espírito Santo. Orcid: https://orcid.org/0000-0002-6162-8489

E-mail: zbomfante@gmail.com

${ }^{2}$ Doutora em Linguística pela Universidade de Lisboa. Professora da Universidade Federal de Alfenas. Orcid: https://orcid.org/0000-0002-0663-670X

E-mail: flavianefc@hotmail.com
} 
Mathematics prioritize the evaluation of the contributions and theoretical implications of the results found in the research for the area, as well as the impacts of the study and application of its results in the social reality.

Keywords: Systemic-Functional Approach; Social Rethorical; Academic Article Genre.

\section{Introdução}

... the systemic analysis shows that functionality is intrinsic to language: this is to say, the entire architecture of language is arranged along functional lines. Language is as it is because of the functions in which it has evolved in the human species (HALLIDAY; MATTHIESSEN, 2004, p. $31)$.

O texto de Halliday e Mathiessen em epígrafe aponta para uma perspectiva sistêmica e funcional da linguagem, justamente por considerar a língua como um recurso para produção de significados, sendo esses significados resultados de padrões sistêmicos de escolhas. Tais escolhas revelam os movimentos possíveis de serem realizados com o texto, pertencente a um determinado gênero. Nesse processo de realização do texto por meio de escolhas, dadas as necessidades socioculturais de comunicação do indivíduo, são colocados em cena elementos grafo-fonológicos, léxico-gramaticais e semântico-discursivos, que estão diretamente relacionados ao contexto de cultura e de situação em que o texto é produzido. A noção de contexto que permeia esse trabalho está ancorada nas contribuições hallidayanas, sendo compreendidas como a representação abstrata que se dá em termos de certas categorias linguísticas relevantes para o texto, algo mais amplo e cultural, ou seja, o contexto cultural. Em linhas gerais, o contexto de cultura refere-se ao propósito e ao significado para os quais o texto foi produzido, apontando para a noção de gênero. O contexto situacional aponta para o sistema semântico da linguagem, um sistema semântico particular, ou um conjunto de subsistemas ao qual está associado um tipo de situação ou contexto social - o registro.

Ao observarmos os movimentos de linguagem no processo de instanciação de um texto, compreendido aqui como a relação entre Sistema e Texto, ou seja, o sistema linguístico instanciado em forma de texto, podemos refletir como os gêneros circulam em seus contextos de uso e como os usuários deles se apropriam para fins de comunicação. Ao buscarmos diálogo nas palavras de Bakthin (2000), a atividade humana é inesgotável, portanto, o repertório de gêneros do discurso amplia-se e se diferencia dentro de uma esfera de comunicação, o que torna possível aos usuários dominar aqueles com os quais se engajam cotidianamente nas práticas sociais. Nesse sentido, o percurso deste trabalho tem sua origem em uma reflexão atenta ao movimento dialético entre a linguagem e o seu uso social, a partir perspectiva sistêmico-funcional da linguagem de Halliday (1985), Halliday e Hasan, (2002) e Martin e Rose (2008) e aliado ao interesse em perspectivar a constituição discursiva da escrita acadêmica, 
com foco na léxico-gramática e nas funções desempenhadas nos contextos sociais, recorrendo, portanto, às considerações de Motta-Roth (2001;2006) Motta-Roth e Hendges (2010).

No Brasil, pesquisadores do grupo Sistêmica Através das Línguas (SAL) têm investigado instanciações de gêneros na perspectiva da Linguística Sistêmico-Funcional (LSF) e direcionado muitas pesquisas para a linguagem acadêmica. A escrita acadêmica tem despertado interesse de diversos estudiosos como Motta-Roth (1998, 2001, 2018), Motta Roth e Hendges (2010), Santos (2013), Marinho (2010), Biasi-Rodrigues (2001, 1999a, 1999b), Bárbara e Moyano (2001), Vian Junior (2011). Paralelamente, no cenário internacional, diversos trabalhos têm se detido em mapear diferentes aspectos da interação escrita para produzir abordagens pedagógicas atinentes aos gêneros acadêmicos, como Martin (1998), Bazerman (1998), Swales (1990, 2004) e Christie (2002, 2004). Assim, a partir da perspectiva elucidada, nosso objetivo é discutir como as noções de texto, contexto, metafunções, registro e gêneros da LSF podem potencializar a produção escrita no ensino superior.

Diante de um cenário que requer a apropriação da escrita no contexto de pesquisa para a produção científica, torna-se imprescindível o domínio de um repertório de gêneros específicos para se inserir e dialogar nessa esfera. Compreendemos a universidade como um domínio da atividade humana onde circulam "um sistema e conjuntos de gêneros", conforme proposto por Swales (2004) e Bhatia (2004). Ao direcionarmos o nosso olhar para o ambiente universitário, observamos que, para interagir nessa comunidade é preciso, segundo MottaRoth (2008), compreender a totalidade de interação dos eventos comunicativos que nela existe ou ligados a ela, desde as atividades de laboratório de pesquisa até atividades em programas de pós-graduação. Dadas as características dessa esfera, compreender a noção de conceito de sistema de gênero torna-se relevante, pois possibilita entender como cada texto realiza sua parte nessa rede, ou seja, como os textos, juntos, delimitam as atividades do grupo social.

Uma das formas mais recorrentes de tornar público o conhecimento produzido pela atividade de pesquisa entre pesquisadores, alunos, professores de graduação e pós-graduação é a publicação do artigo acadêmico, embora muitos gêneros da esfera acadêmica socializem a atividade de pesquisa, tais como o seminário, palestras, capítulo de livro, resenha crítica, debate, apresentação em congressos, dentre outros. $O$ artigo trata de um gênero bastante específico do contexto acadêmico, com uma circulação restrita a esse meio, visto que periódicos científicos não estão em toda parte para consumo da população. Considerando essas especificidades, a escrita na universidade é uma exigência seja para a socialização de conhecimentos, seja para comprovação de produtividade em tempos de "publique ou pereça" ou para verificação de aprendizagem.

$\mathrm{O}$ ato de escrever no contexto acadêmico é uma atividade complexa para muitos que ingressam no ensino superior, devido à pouca familiaridade com o sistema e conjunto de gêneros dessa esfera. Nesse cenário, é necessário conceber o ato de escrever como uma prática situada em um contexto cultural, requerendo outros letramentos, desdobrando-se em 
novas maneiras de compreender, interagir, interpretar e organizar o conhecimento.

Com base em tais ponderações, o presente trabalho propõe uma reflexão sobre as contribuições da abordagem sistêmico-funcional para compreender a relação entre linguagem e contexto situacional e cultural na produção do artigo acadêmico. Além destas considerações iniciais, o trabalho é constituído de três partes principais, cujos objetivos são: (i) apresentar a discussão epistemológica das premissas que norteiam a perspectiva sistêmico-funcional da linguagem; logo em seguida (ii) articular essas premissas ao processo da escrita acadêmica, mais precisamente o gênero artigo acadêmico e, por último, (iii) enfatizar as possibilidades do uso da abordagem sistêmico-funcional na escrita acadêmica.

A nossa investigação é constituída por um corpus $^{3}$ de análise cujos artigos foram produzidos por 13 alunos matriculados na disciplina intitulada " $A$ escrita nas práticas de Letramento Acadêmico", ministrada no curso de Pós-Graduação em Ensino na Educação Básica da Universidade Federal do Espírito Santo - CEUNES/UFES. O curso de Pós-Graduação em Ensino na Educação Básica tem um público-alvo bastante heterogêneo, em grande medida, professores de diversas áreas do conhecimento (Linguagens e Códigos, Ciências Humanas, Ciências da Natureza e Matemática) que possuem curso de licenciatura e especialização, além de atuarem na educação básica. Vale ressaltar que muitos alunos/professores relatam, de forma recorrente, dificuldades de se inserirem na esfera acadêmica por conta da pouca familiaridade com a escrita de projetos, resenhas, artigos, dissertações, dentre outros. Assim, a referida disciplina foi criada a fim de possibilitar a reflexão sobre as práticas sociais de linguagem no contexto acadêmico, problematizando questões sobre discurso, gênero, texto, registro, dialogismo, polifonia, interdiscursividade, intertextualidade, noções de autoria e identidade na escrita acadêmica, bem como possibilitar eventos de letramento de gêneros acadêmicos. É partir desse cenário que situaremos algumas reflexões epistemológicas e analíticas.

\footnotetext{
${ }^{3}$ Trabalho desenvolvido no LEAL-Laboratório de Pesquisa em Ensino e Aprendizagem de Línguas do CEUNES/ UFES como parte do projeto intitulado "O ensino de línguas e a formação de professores na perspectiva dos novos letramentos e multiletramentos no norte do estado do Espírito Santo", com apoio do Edital FAPES/CNPq no 04/2017, processo sob o número 80657834 e registro da Pró-Reitoria de Graduação - PRPPG 7749/2019. O Corpus do presente trabalho foi apreciado mediante autorização e assinatura de Termo de Consentimento Informado dos participantes. O referido termo situa o compromisso com a conduta ética do trabalho, não identificando os participantes e dados produzidos usados exclusivamente para gerar informações para a pesquisa relatada.
} 


\title{
Os preceitos da abordagem sistêmico-funcional: as noções de texto, contexto, metafunções, registro e gênero
}

Texto, contexto e metafunções

A abordagem sistêmico-funcional, formulada pelo linguista Michael Alexander Halliday (1978, 1985), Halliday e Matthiessen $(2004,2014)$ e desenvolvida por pesquisadores de várias partes do mundo, dentre os quais podemos destacar Eggins (1994), Thompson (2003), Martin e Rose (2003), Martin (1985, 2000), Meurer (2002, 2004), Vian Junior (2006, 2011) dentre outros, concebe a linguagem a partir de um sistema social e cultural, o que implica interpretála dentro do contexto sociocultural no qual se realiza. Essa abordagem está centrada na noção de 'função', pois considera a língua como uma rede de sistemas interligados dos quais o falante faz uso (base funcional) para produzir significados (base semântica).

Além de ser funcional no processo de produção de significados, a linguagem é entendida como um sistema semiótico, ou seja, um sistema de codificação convencionalizado, organizado como uma gama de escolhas, constituindo-se, assim, em uma forma de representação da experiência humana. Assim, a língua se organiza em torno de redes interdependentes de escolhas, que por sua vez correspondem a funções básicas da linguagem, constituindo-se, assim, em um sistema de construção e reconstrução de significados a cada vez que o sistema é acessado.

Uma possiblidade para compreender a linguagem pela perspectiva sistêmico-funcional é agasalhar a ideia de que os significados são realizados a partir de uma noção

\begin{abstract}
metafuncional e estratificada, em que os sentidos interpessoais, ideacionais e textuais ocorrem simultaneamente para a construção de significados no texto e em que, ao mesmo tempo, as escolhas em estrato projetam construções no estrato seguinte. As escolhas no estrato grafo-fonológico são a realização de escolhas no estrato lexicogramatical. Estas, por seu turno, estão realizando escolhas no estrato semântico-discursivo, sendo que tais escolhas ocorrem em contextos de cultura e de situações distintos (VIAN JUNIOR; MENDES, 2015, p. 164).
\end{abstract}

A partir das ideias trazidas pelos autores acima, os significados são construídos em um determinado contexto e os recursos linguísticos realizam esses significados sob forma de texto ${ }^{4}$. Nessa perspectiva, compreendemos a noção de texto como "qualquer instância de

\footnotetext{
${ }^{4} \mathrm{Na}$ perspectiva sistêmico-funcional o texto é visto sob duas perspectivas: como processo - um processo contínuo de escolha semântica, um movimento através da rede de potencial de significado e
} 
linguagem viva que desempenha algum papel em um contexto de situação" (HALLIDAY; HASAN, 2002, p. 10).

Assim, os textos produzidos na esfera acadêmica são tomados aqui como um processo interativo de troca social de significados com a comunidade acadêmica. Esses significados realizados por recursos linguísticos, a partir de escolhas semânticas, socializam os propósitos comunicativos de seus falantes na propagação do conhecimento produzido ou sistematizado. Nesse sentido, o texto é qualquer interação, negociação de significados em múltiplas modalidades (verbal, visual, gestual, sonoro etc.) em um contexto de uso. Em outros termos, ele é o resultado de toda e qualquer situação de interação, não podendo ser interpretado sem levar em conta seu contexto de produção.

Indispensável a essa noção de texto é a noção de contexto proposta por Halliday a partir das pesquisas do antropólogo Malinowski e trazidas para os estudos da linguagem por meio do trabalho de Firth (1935). O contexto de cultura está relacionado aos modos de vida, costumes, valores e crenças. Assim, todo texto é produzido e interpretado dentro de um contexto cultural, cujo membro de uma cultura tem acesso ao significado potencial na sua linguagem. Esse significado potencial é o sistema semântico da linguagem interpretado no contexto de situação, conforme ilustra a figura abaixo, que organizamos a partir de círculos cotangenciais:

Figura 1 - Complexo sistêmico-funcional.

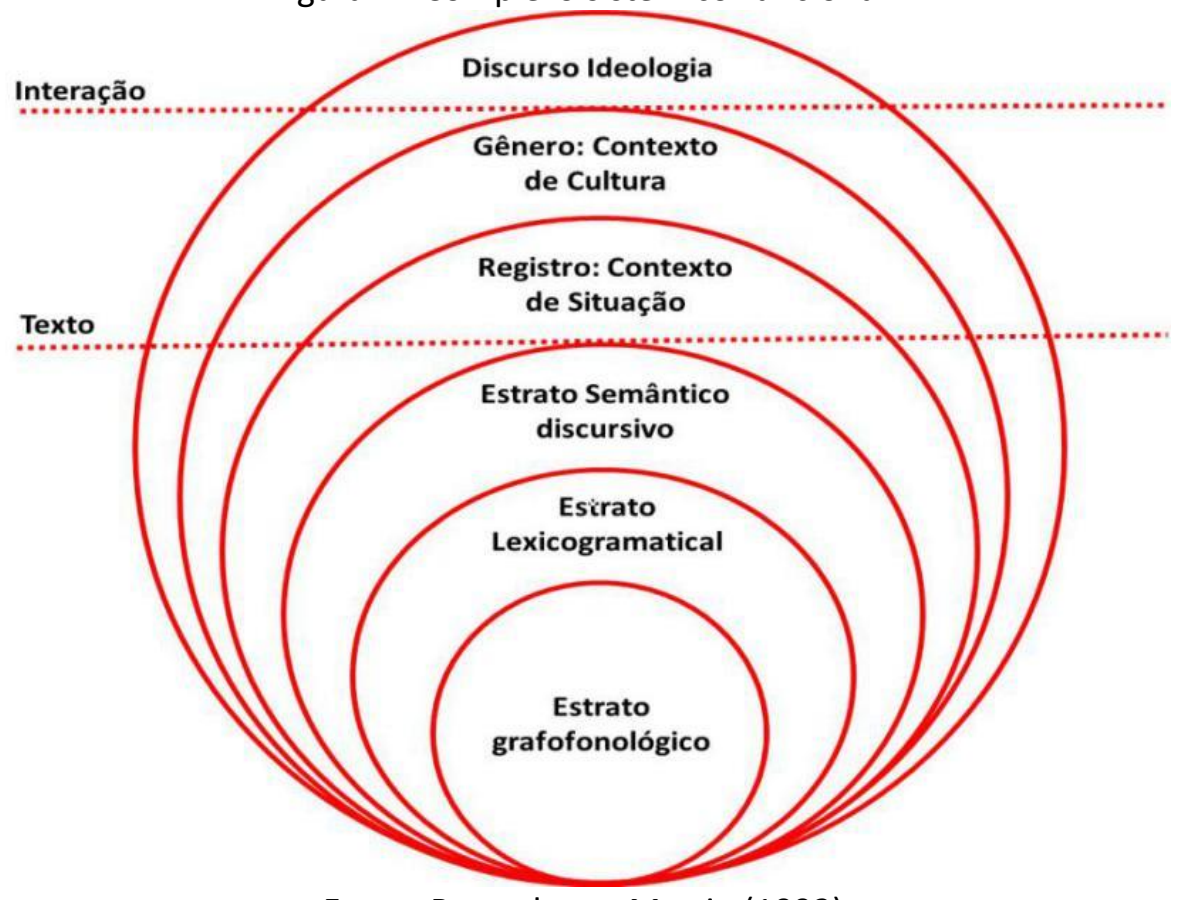

Fonte: Baseado em Martin (1992)

produto - no sentido de que o texto pode ser gravado, estudado, tendo uma construção que pode ser representada em termos sistemáticos. 
O contexto de situação traz as propriedades gerais da situação de comunicação que funcionam como determinantes do texto, demarcando quais configurações semânticas irão figurar na materialidade textual. Para Halliday e Hasan (2002, p. 12) ele é o "ambiente em que o texto se desenvolve". Em outras palavras, é no contexto de situação em que estão os aspectos extralinguísticos dos textos, capazes de determinar os padrões linguísticos denominado registro - a serem utilizados na produção textual. A relação entre contexto de cultura e contexto de situação resultará em diferentes textos, com semelhanças e diferenças. Nesses parâmetros, o nível do texto escrito equivale ao estrato grafofonológico e lexicogramatical, a interação está no estrato do registro (contexto de situação) e do gênero (contexto de cultura), sendo o contexto, segundo Motta-Roth (2008, p. 355), o plano mais amplo, do discurso e da ideologia, visto que "o gênero que constitui a cultura está num nível intermediário entre a situação e o contexto da totalidade da sociedade".

A partir dessas premissas, um dos objetivos centrais de trabalhar a escrita no ensino superior é levar o aluno a compreender sua escrita dentro de um contexto; esse processo de escrita resultará em escolhas semióticas, a partir dos seus propósitos comunicativos. A questão que se coloca é a necessidade de se analisar a relação entre práticas sociais e discursivas para vislumbrar como a linguagem se articula nesse espaço. Nesse sentido, é importante os alunos, nessa esfera, observarem como a linguagem é articulada e faz a mediação nas atividades desempenhadas na sala de aula, palestras, seminários, laboratórios, orientações etc., ou seja, num conjunto de gêneros, bem como os papéis assumidos nessas interações, visto que a formação no ensino superior prevê uma formação para a escrita acadêmica. Ao mesmo tempo, por meio dela, ocorre também um extenso processo de socialização. É relevante ressaltar ainda a necessidade de perceber como práticas discursivas e de linguagem vão se constituindo dentro das áreas de ensino, trazendo características próprias, visto que não há uma unicidade no discurso científico que consequentemente irá se materializar sob a forma de texto. Adicionalmente, Grossmann (2015, p.97) afirma que a "variação do campo do discurso científico é o único meio para preservar a unicidade de uma macrocategoria como o discurso científico", que encobre as diferenças disciplinares e metodológicas que marcam a escrita acadêmica. Assim, é elementar uma contextualização e sensibilização para observar os comportamentos, os costumes, os valores, os posicionamentos, as modalizações, a organização textual na produção textual do discurso científico de uma área de conhecimento.

Nesses parâmetros, a noção de texto deve ser tomada como um processo e um produto de significado social que se desenvolve dentro de um contexto de situação, por meio de uma relação sistemática entre ambiente social e organização funcional da linguagem, que projeta a relação entre texto e contexto como um fenômeno semiótico, ou seja, com diferentes modos de significar. Por extensão, uma das maneiras de observarmos a sinergia entre texto e contexto de situação é lançar os olhos para a interação e o modo como os sujeitos assimilam 
o ambiente social em que os significados são negociados. A abordagem sistêmico-funcional aponta para variáveis contextuais campo, relações e modos, baseados dos trabalhos de Firth, Ellis, Berg e outros, nos anos 1950. Essas três variáveis contextuais estão ligadas às metafunções, realizadas pela descrição sistêmica de Halliday da teoria sistêmico-funcional: ideacional, interpessoal e textual (HALLIDAY, 1978, 1985).

As metafunções abrangem todas as áreas da linguagem e estão correlacionadas com as variáveis contextuais: campo e metafunção ideacional, ligadas à natureza da representação da experiência da linguagem; relações e metafunção interpessoal, referindo-se à natureza das relações interpessoais na linguagem; e modo e metafunção textual, correspondendo às escolhas feitas na língua para organizar o texto como mensagem, o que inclui as estratégias retóricas do escritor, possibilitando a textualização da experiência de maneira coerente, em outros termos, relaciona-se ao modo da comunicação do texto (HALLIDAY, 1978), conforme sintetiza a Figura 2 abaixo:

Figura 2 - Estratificação do contexto de situação

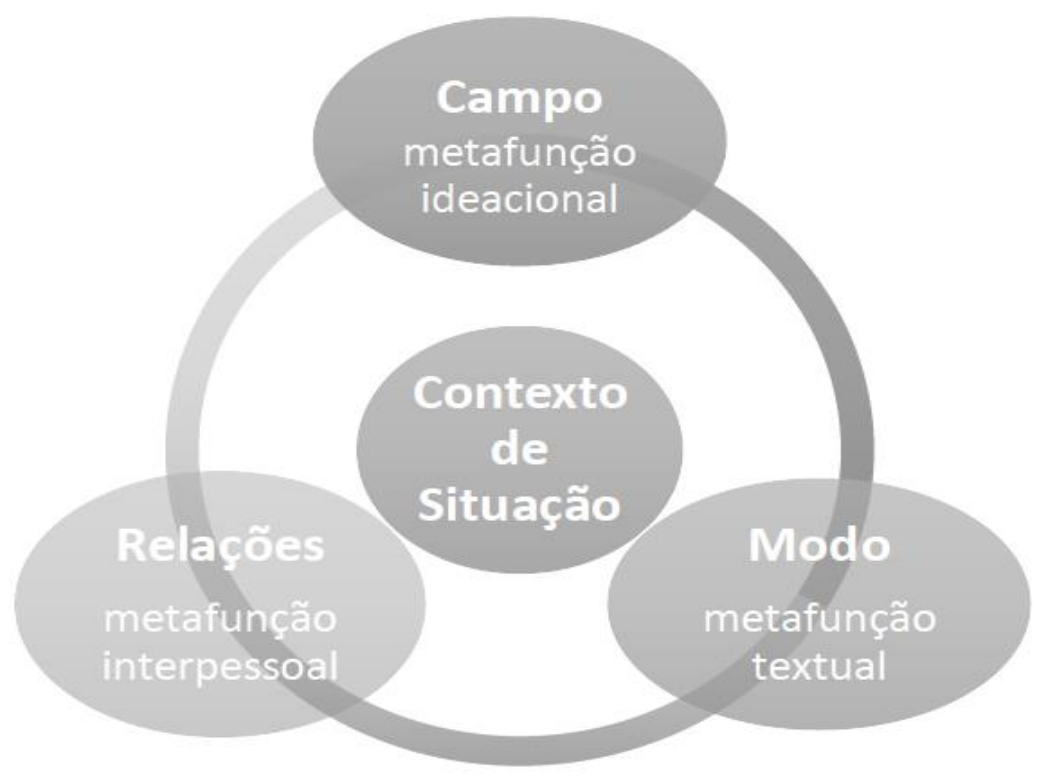

Fonte: Baseado em Halliday $(1978,2014)$

A dimensão semiótica de uma situação de interação se constitui na léxico-gramática do texto, podendo ser perceptível no registro de um gênero específico. O gênero, por sua vez, estrutura as instituições. Assim, podemos perceber a variação do registro, a partir de um contexto de situação, de alunos na área de química, matemática, biologia, pedagogia, educação do campo e letras na produção de um artigo acadêmico para avaliação de disciplina, 
bem como do pesquisador iniciante que busca se inserir e dialogar na comunidade científica de uma determinada área. No ensino da escrita na universidade, a partir das contribuições da perspectiva sistêmica, é relevante ressaltar como os três tipos de significado (ideacional, interpessoal, textual) concretizam as opções disponíveis em um dado contexto. É relevante que os alunos percebam que eles escrevem em um dado contexto e que os textos produzidos materializam significados a partir de escolhas léxico-gramaticais em relação à variedade de significados pertencentes a um dado gênero, configurando, assim, o registro do gênero.

A esfera acadêmica é um bom exemplo da interface entre contexto de situação e o contexto de cultura, onde um conjunto de gêneros circulam. Qualquer texto produzido nessa esfera é um processo que vai se constituindo em concatenação com várias outras situações: os debates em sala mediados pelo professor; as anotações dos alunos, as orientações, as observações de livros, as aulas expositivas, a dimensão conceitual do que está se objetivando depreender, a relação estabelecida entre professor e aluno, a relação autor de livros, capítulos, artigos com o leitor, bem como o modo de exposição escrita ou oral. Em todos esses movimentos está o contexto de situação, cujos significados derivam da universidade enquanto uma instituição na cultura: os conceitos de educação, conhecimento, ensino, escrita, distintos do senso comum; a noção de currículo e de disciplinas para ensino etc. Todos esses fatores constituem o contexto de cultura e determinam, coletivamente, a maneira pela qual o texto é interpretado no contexto de situação.

Nesta via, em qualquer situação de aprendizagem de uma língua, mais especificamente na escrita da esfera acadêmica, é necessário conscientizar o aluno sobre a relação entre linguagem e contexto, levando-o a aprender a língua, por meio da língua e sobre a língua, segundo Halliday (1985). Buscando ressaltar essa relação entre texto e contexto, Motta-Roth (2006, 2008) em sua vasta produção e notável contribuição sobre escrita acadêmica, busca articular os princípios da perspectiva sistêmico-funcional para que os alunos percebam as relações entre texto e contexto da linguagem na produção do gênero artigo acadêmico, conforme sintetizamos no esquema abaixo: 
Figura 3 - Configuração do contexto de situação no gênero artigo acadêmico

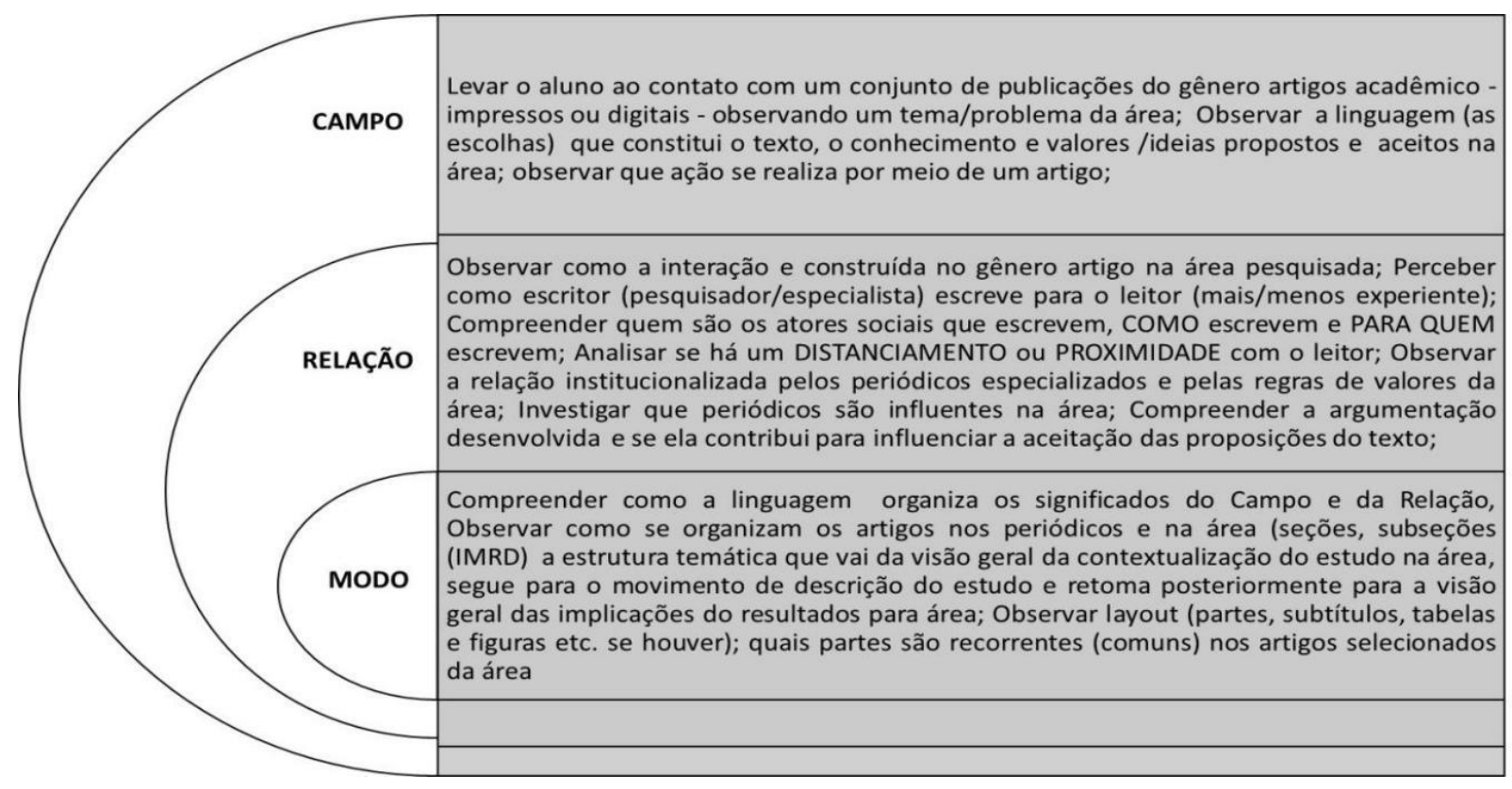

Fonte: Baseado em Motta-Roth (2006)

Conforme o esquema acima, ao sensibilizar o aluno para as relações entre texto e contexto a fim de refletir sobre o papel da linguagem na produção de conhecimento de uma determinada área, potencializa-se a compreensão de como as escolhas semióticas são operacionalizadas desde o estrato grafo-fonológico, sem excluir sua conexão com os demais estratos, ou seja, busca-se compreender e interpretar as escolhas passando pelo estrato lexicogramatical, pelo estrato semântico discursivo, até chegar aos contextos que motivam a produção escrita. As escolhas semióticas, por seu turno, realizadas na interação, no que se refere ao Campo (tópico ou foco da atividade), Relações (papel das relações de poder e solidariedade na interação) e Modo (papel da língua: oral, escrita, multimodal) marcam a variação do Registro do Gênero, tópicos que abordaremos na seção seguinte.

Ao enfatizarmos o termo 'escolhas' para realização do texto, situamos que o conjunto de escolhas semióticas realizadas a partir dos objetivos do produtor reflete o estilo do texto. O termo estilo está ligado às proposições de Kress (2010) quando afirma que o conjunto de possiblidades de recursos da língua leva o produtor do texto a realizar escolhas. Essa política de escolhas realizadas descrevem o estilo do texto. Por extensão, o estilo do texto reflete as configurações do registro realizadas metafuncionalmente no nível do campo, relações e modo. Kress ainda acrescenta que a política de estilo vai dimensionar a estética dos textos. Nesse certame, diferentes textos e registros circulam na esfera acadêmica e refletem a dimensão contextual mais abstrata - a ideologia do discurso científico. A Figura 4 abaixo explicita essa interrelação: 
Figura 4 - Interrelação de Estilo, Estética e Variáveis de Registro

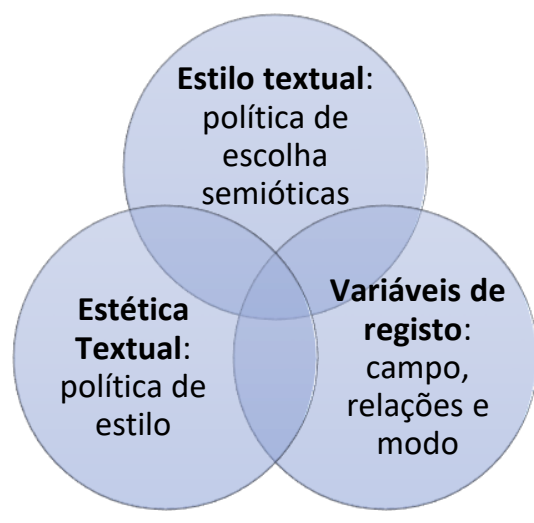

A partir do esquema acima, vemos que a interrelação entre políticas de escolha e de estilo irão marcar o registro do gênero. Essas escolhas serão refletidas no nível lexicogramatical pelo tripé metafuncional da linguagem. Na seção seguinte, ampliamos a discussão em torno a perspectiva sistêmica sobre a noção de Gênero e Registro.

\section{Gênero e Registro}

Considerando a relevância de compreender como os gêneros circulam numa esfera e são apropriados pelos usuários, Bhatia afirma que

[...] a análise de gêneros tem se tornando extremamente popular nos últimos anos. $O$ interesse pela teoria dos gêneros e suas aplicações não se restringe mais a um grupo específico de pesquisadores de uma área particular ou de um setor qualquer do globo terrestre, mas cresceu a ponto de assumir uma relevância muito mais ampla do que jamais foi imaginado (BHATIA, 1994, p. 229).

As proposições de Bhatia colocam o estudo e a compreensão dos gêneros num lugar de destaque e tece diálogos com o pensamento de Bakthin (2000), visto que para o filósofo russo os gêneros são realidades imprescindíveis a ações no mundo; dominar um repertório de gêneros é fundamental para a ação em sociedade, dado que é através dos gêneros que os discursos são transformados em ação. Nesse movimento, asseveramos que o domínio dos gêneros (conjunto de gêneros) para se comunicar numa esfera de atividade humana - aqui situamos a esfera universitária - é condição sine qua non para sobrevivência e ação dos sujeitos que ali se inserem. A rigor, o uso do termo domínio não remete apenas à forma ou à 
composição, ou ao 'formato' do texto, como demasiadamente tem sido tratado no ensino da escrita, mas à compreensão da situação de comunicação que possibilita escolhas para realização de significados (ideacionais, interpessoais, textuais) que marcam o registro e permite a instanciação do gênero.

O ponto de partida para o estudo dos gêneros do discurso pela prisma sistêmicofuncional, segundo Vian Junior (2011), é a intepretação do contexto sociocultural em que um texto é produzido e, para compreender a relação do texto com os referidos contextos, podemos nos questionar: (i) O que está acontecendo? (ii) quem participa desse evento? (iii) qual o papel da linguagem? Esses questionamentos nos permitem refletir e acessar imediatamente o texto ao contexto de situação, possibilitando inferir quais elementos estão presentes no texto. Não se limitando ao contexto situacional, para o autor, alcançamos também o contexto cultural - uma noção mais ampla - isto é, os modos, os valores, os comportamentos, os pontos de vista do campo científico em que se inserem e, por conseguinte, os gêneros que circulam nesse contexto. Nesse movimento, os alunos começam a se engajar, articular as vozes desse campo científico, bem como a usar os discursos e entendimentos da disciplina para a construção de uma identidade. Segundo Hyland (2012, p.3), essa construção de identidade "pode ganhar reconhecimento e reforço por meio do uso desses discursos".

Os gêneros, a partir das contribuições de Martin e Rose (2003, p.8), são compreendidos como "diferentes tipos de textos que representam vários contextos sociais" 5 , em outros termos, um processo social orientado para um objetivo, organizado em estágios e realizado pelo registro - o contexto de situação. Na concepção de Martin (2000), o registro possibilita a instanciação do gênero. Por extensão, o registro organizado de acordo com o nível do campo, das relações e do modo, reflete a diversidade metafuncional no nível da linguagem materializada pela léxico-gramática, enquanto no nível dos processos sociais é o gênero. Nessa perspectiva, de acordo com Martin (2000), o gênero pré-seleciona as variáveis de registro, sendo instanciado mediante escolhas das variáveis de registro, estabelecendo a interrrelação gênero-registro-linguagem, conforme sintetiza o esquema a seguir:

Figura 5: Interrelação gênero-registro-linguagem

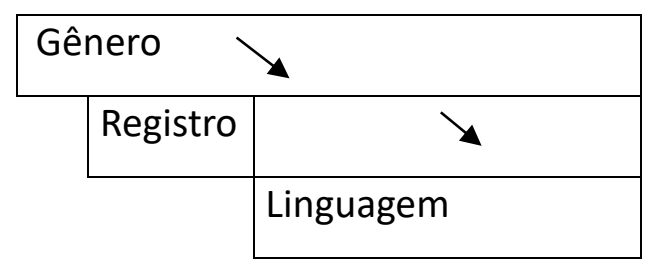

Fonte: Baseado em Martin (1992, p.495)

\footnotetext{
${ }^{5}$ Nossa tradução de: "Diferent types of texts that enact various types of social context" (MARTIN; ROSE, 2007, p. 8).
} 
Ao buscarmos articular a inter-relação de gênero-registro-linguagem, a partir da visão sistêmica, para artigo acadêmico ${ }^{6}$, depreendemos que esse gênero é produzido em contexto social e cultural específico, organizado em estágio que pode ter variação em decorrência da área de conhecimento. O artigo acadêmico, de modo, geral, segundo Motta-Roth (2001) e Motta-Roth e Hendges (2010), apresenta as seguintes seções: Introdução, Revisão de Literatura, Metodologia, Resultados e Discussão e Conclusão ${ }^{7}$. Seguindo a perspectiva de Swales (1990), que concebe o gênero como um tipo de ação social, estas cinco seções, por sua vez, seriam realizadas por meio de cinco movimentos (moves), associados às suas respectivas estratégias (que podem ou não coexistir em um mesmo movimento) para a sua instanciação e atingimento de seus propósitos comunicativos, conforme é didaticamente elaborado na Figura 6 abaixo:

Figura 6 - Padrão descritivo de organização textual das seções que compõem artigos acadêmicos

\begin{tabular}{|l|}
\hline 1 Oo movimento: INTRODUÇÃO \\
\hline Estratégia 1: Fazendo generalizações sobre o assunto a ser tratado $e / o u$ \\
Estratégia 2: Contextualizando o problema dentro da área do conhecimento e/ou \\
Estratégia 3: Formulando questionamentos sobre o assunto e/ou \\
Estratégia 4: Revisando itens de pesquisa prévia sobre o tema e/ou \\
Estratégia 5: Tecendo argumentos contrários aos estudos prévios e/ou
\end{tabular}

\footnotetext{
${ }^{6}$ Segundo Morris, (1966 apud Crookes 1986), Motta-Roth (2001) e Swales (2004), o gênero artigo acadêmico pode ser classificado em: Artigos Teóricos, Artigos Experimentais e Artigos de Revisão. De maneira sucinta, explicitamos algumas informações sobre essa classificação. Os Artigos Teóricos tratam de assuntos e/ou pesquisas que não envolvem coleta de dados, muito comum à pesquisa experimental. Para Swales, os Artigos Experimentais baseiam-se em estudo sobre dados coletados. Motta-Roth acentua que esses artigos apresentam fatos ligados a uma pesquisa de caráter experimental, abordando um problema específico e se distinguem de Artigos Científicos Empíricos que não relatam uma pesquisa desenvolvida em um ambiente experimental controlado, porém trazem resultados da observação direta dos fenômenos percebidos pela experiência. Os Artigos de Revisão levam informações a uma comunidade de pessoas, oferecendo oportunidade de reflexão sobre o passado e sobre eventos futuros, possibilitando que o autor contribua com a área de estudo. Os artigos de Revisão ainda se desdobram em outras categorias, segundo Swales (2004) e Noguchi (2001): (1) artigos que apresentam uma visão histórica de uma faceta de uma área de estudo;(2) artigos que descrevem a situação atual de uma área de estudo; (3) artigos que propõem uma teoria; (4) artigos que chamam a atenção para alguma questão problemática de uma área de estudo.

${ }^{7}$ Motta-Roth e Hendges (2010) consideram como seções do artigo acadêmico apenas a Introdução, a Metodologia e os Resultados e Discussão - o chamado padrão IMRD, alegando que a Revisão de Literatura pode ocorrer dentro da seção de Introdução e a Conclusão dentro da seção Resultados e Discussão. Contudo, ressalvam que também é possível encontrar a ocorrência de uma seção específica para Revisão de Literatura e de Conclusão, padrão de organização textual adotado pelas autoras do presente trabalho.
} 
Estratégia 6: Dando continuidade a uma tradição de pesquisa já estabelecida e/ou Estratégia 7: Destacando a relevância do tema e/ou

Estratégia 8: Indicando lacunas ainda a preencher no conhecimento estabelecido e/ou Estratégia 9: Apresentando o objetivo e a justificativa do estudo e/ou

Estratégia 10: Buscando preencher a lacuna no conhecimento e/ou

Estratégia 11: Anunciando principais resultados e/ou

Estratégia 12: Delineando a visão geral da organização do artigo

2 movimento: REVISÃO DE LITERATURA

Estratégia 1: Estabelecendo interesse profissional no tópico e/ou

Estratégia 2: Fazendo generalizações sobre o tópico e/ou

Estratégia 3: Citando pesquisas prévias e/ou

Estratégia 4: Estendendo pesquisas prévias e/ou

Estratégia 5: Contra argumentando pesquisas prévias e/ou

Estratégia 6: Indicando lacunas em pesquisas prévias

$$
\text { 3o movimento: METODOLOGIA }
$$

Estratégia 1: Descrevendo o corpus ou participantes da pesquisa e/ou

Estratégia 2: Descrevendo os materiais usados na coleta de dados e/ou

Estratégia 3: Descrevendo os procedimentos e/ou

Estratégia 4: Descrevendo a análise dos dados

4o movimento: RESULTADOS E DISCUSSÃO

Estratégia 1: Recapitulando a informação metodológica e/ou

Estratégia 2: Descrevendo dados obtidos e/ou

Estratégia 3: Realizando análises e/ou

Estratégia 4: Interpretando resultados e/ou

Estratégia 5: Comparando a descoberta com a literatura (se há concordância ou contraste) $e / o u$

Estratégia 6: Sintetizando principais resultados ou evidências

\section{5o movimento: CONCLUSÃO}

Estratégia 1: Elaborando generalizações acerca das descobertas principais e/ou

Estratégia 2: Identificando uma ou duas descobertas para tratar em detalhe e/ou 
Estratégia 3: Situando os resultados na literatura da área e/ou

Estratégia 4: Avaliando as contribuições e implicações teóricas para a área e/ou

Estratégia 5: Mencionando limitações da pesquisa e/ou

Estratégia 6: Sugerindo pesquisas futuras e/ou

Estratégia 7: Considerando implementações práticas a partir dos resultados obtidos

Fonte: Adaptado de Motta-Roth e Hendges (2010)

Como resultado, as regularidades acima observadas no gênero artigo acadêmico apontariam para um contexto social e cultural mais amplo em que a linguagem é utilizada, "a fim de cumprir demandas comunicativas específicas, responsáveis por moldar o gênero, determinando sua estrutura interna e impondo limites quanto às possibilidades de ocorrências linguísticas e retóricas" (CARVALHO, 2010, p.116-117).

Adicionalmente, inserimos as seções recorrentes à estrutura esquemática: resumo/abstract, palavras-chave/keywords, introdução, revisão de literatura, fundamentação teórica, metodologia, análise de resultados e discussão, considerações finais, referências, anexos etc.). Essas variações estão ligadas a fatores como área de produção em que o pesquisador se insere, linha de pesquisa, metodologia adotada. É relevante pontuar que o discurso acadêmico, como um todo, prescreve normas, o seu registro sofre regulações, ou seja, é perpassado por questões de hegemonia.

Considerando as características do discurso acadêmico e as regulações do seu registro, vemos que este instancia o gênero artigo acadêmico que expressa significados de acordo com seus amplos propósitos sociais - engajar, argumentar, informar, defender e discutir pontos de vista, refletir dimensões conceituais etc. De maneira geral, a escolha do gênero artigo acadêmico, quando lemos e escrevemos em nossas práticas sociais, é reportar um estudo. Como artigos envolvem leitores, o papel de analista ativo no texto é central, eles precisam estar convencidos da relevância do estudo reportado, para tanto, o autor precisa organizar seu texto, expor seus resultados, reflexões, pontos de vista, argumentar, concluir utilizando as convenções próprias da área do saber a que se inscreve.

Partindo do princípio de que o gênero é uma noção abstrata que remete às configurações de significados em múltiplas modalidades (multimodalidade), o artigo acadêmico na sua estética textual, em várias áreas do saber, socializa informações, tece sua argumentação, comunica e representa o conhecimento por meio da utilização de vários modos e recursos semióticos: gráficos, esquemas, infográficos, tabelas, fluxogramas, imagens (com recursos de cores, orientação de código $^{8}$ : naturalística, tecnológica, abstrato etc.) dentre

\footnotetext{
${ }^{8}$ Termo utilizado por Kress e van Leeuwen (2006) para designar um conjunto de princípios abstratos que indicam a forma como os textos são codificados por grupos sociais específicos, dentro de contextos
} 
outros, proporcionado formas diversas de representação do saber, bem como engajamento do leitor na construção da interação na e pela leitura, suscitando, assim, um nova lente para a leitura e produção desse gênero.

Pensar a noção de gênero pela perspectiva sistêmico-funcional é pensar como os textos são organizados em fases/estágios para alcançarem propósitos sociais. Nas práticas sociais, os gêneros são criados, desenvolvidos e modificados, sendo que seus propósitos são orientados a partir das demandas das instituições, entidades, atividades, eventos, participantes e interações. As noções de Gênero e Registro nos permitem perceber a variação dos textos, as diferenças entre eles por meio das motivações contextuais. Essas diferenças podem ser percebidas e analisadas se direcionarmos o nosso olhar para a estruturação do texto em estágios e as características do gênero. O registro, a partir das considerações de Martin (1992[2000]), instancia o gênero e, consequentemente, podemos nos ancorar nele como ponto de partida para análise do texto e, consequentemente, para sua escrita. A noção de gênero e registro para a sistêmica projeta a materialização linguística do texto.

\section{A perspectiva Sistêmico-Funcional nas relações entre o contexto universitário e o texto artigo acadêmico}

Com a finalidade de verificar em que medida o modelo de organização textual do gênero artigo acadêmico proposto por Motta-Roth e Hendges (2010) se aplica em textos oriundos de áreas do conhecimento distintas no contexto brasileiro de pesquisa, estabelecemos uma comparação entre os artigos produzidos por 13 alunos das áreas de Ciências Humanas e Ciências da Natureza e Matemática de um Programa de Pós-graduação em Ensino na Educação Básica, observando as principais características de organização textual de cada domínio do saber e se há diferenças entre suas respectivas culturas e práticas disciplinares.

A Tabela 1 abaixo sintetiza os movimentos e estratégias mais recorrentes adotadas pelos alunos filiados à área de Humanidades:

Tabela 1 - Configuração dos movimentos e suas estratégias nos artigos da área de Ciências Humanas

\begin{tabular}{|c|c|c|c|c|c|c|c|c|c|}
\hline \multicolumn{2}{|c|}{ Artigos } & LIN & LIN & LIN & ED & ED & ED & HI & Total \\
\cline { 1 - 10 } Movimentos & Estratégias & & & & & & & & \\
\hline & $E 1$ & & $\mathrm{X}$ & & & & & & $\mathbf{1}$ \\
\cline { 2 - 9 } & $E 2$ & $\mathrm{X}$ & & & $\mathrm{X}$ & & $\mathrm{X}$ & & $\mathbf{3}$ \\
\hline
\end{tabular}

institucionais específicos, especialmente ligados aos diferentes princípios de realidade. 


\begin{tabular}{|c|c|c|c|c|c|c|c|c|c|}
\hline \multirow{10}{*}{ M1 } & E3 & $X$ & & & & $X$ & & & 2 \\
\hline & $E 4$ & & & $X$ & $X$ & & & $x$ & 3 \\
\hline & $E 5$ & & & & & & & & 0 \\
\hline & E6 & & & & & & & & 0 \\
\hline & E7 & $X$ & $X$ & $X$ & & $X$ & & & 4 \\
\hline & E8 & & & $X$ & $X$ & & & & 2 \\
\hline & E9 & $X$ & $X$ & $X$ & $X$ & $X$ & $X$ & $X$ & 7 \\
\hline & E10 & & & & & & & & 0 \\
\hline & E11 & & & & & & & & 0 \\
\hline & E12 & & $X$ & $X$ & $X$ & $X$ & $X$ & $X$ & 6 \\
\hline \multirow{6}{*}{$M 2$} & $E 1$ & & & & & & & & 0 \\
\hline & $E 2$ & & & & $X$ & $X$ & & & 2 \\
\hline & E3 & $X$ & $X$ & $X$ & $X$ & $X$ & $x$ & $x$ & 7 \\
\hline & $E 4$ & $X$ & & & & & & & 1 \\
\hline & E5 & $X$ & & & & & $X$ & & 2 \\
\hline & E6 & $X$ & & & & & & & 1 \\
\hline \multirow{4}{*}{ M3 } & $E 1$ & & & & & & $X$ & & 1 \\
\hline & $E 2$ & & & & & $X$ & $X$ & & 2 \\
\hline & E3 & & & & & $X$ & $X$ & & 2 \\
\hline & $E 4$ & & & & & $X$ & $X$ & & 2 \\
\hline \multirow{6}{*}{ M4 } & E1 & & & & & & & & 0 \\
\hline & $E 2$ & & & & & $x$ & $x$ & & 2 \\
\hline & E3 & & & & & $X$ & $X$ & & 2 \\
\hline & $E 4$ & & & & $X$ & $X$ & $X$ & & 3 \\
\hline & E5 & & & & & & & & 0 \\
\hline & E6 & & & $X$ & & & & & 1 \\
\hline & $E 1$ & $X$ & $X$ & & & & $X$ & $X$ & 4 \\
\hline
\end{tabular}




\begin{tabular}{|c|c|c|c|c|c|c|c|c|c|}
\hline & $E 2$ & & & & & & & & $\mathbf{0}$ \\
\cline { 2 - 9 }$M 5$ & $E 3$ & & & & & $\mathrm{X}$ & & $\mathrm{X}$ & $\mathbf{2}$ \\
\cline { 2 - 9 } & $E 4$ & & $\mathrm{X}$ & & $\mathrm{X}$ & $\mathrm{X}$ & & & $\mathbf{3}$ \\
\cline { 2 - 9 } & $E 5$ & & & & & & & & $\mathbf{0}$ \\
\hline & $E 6$ & & & $\mathrm{X}$ & & & $\mathrm{X}$ & & $\mathbf{2}$ \\
\hline
\end{tabular}

Ao analisar os dados apresentados acima, podemos verificar a predominância dos movimentos 1, 2 e 5 (Introdução, Revisão de Literatura e Conclusão, respectivamente), remetendo à preocupação por parte da área e da sua comunidade disciplinar com a explicação dos objetivos, justificativa, relevância e escopo geral do trabalho desenvolvido.

Chama a atenção a importância conferida à seção de Revisão de Literatura, resgatando as pesquisas prévias realizadas na área e que, ora assume algumas funções da seção Introdução, ora cumpre algumas funções das seções Resultados e Discussão e Conclusão, ao generalizar descobertas ou avaliar contribuições e implicações teóricas do trabalho para a área. Verifica-se, assim, certo distanciamento dos contornos propostos pelo padrão de organização textual formulado por Motta-Roth e Hendges (2010).

Nessa esteira, também é imprescindível lançar luz sobre as estratégias que não são recorrentes ou adotadas pela cultura disciplinar da área analisada. Na Introdução, não parece ser habitual explicitar os argumentos contrários aos estudos realizados anteriormente, ou mesmo a continuidade a uma tradição de pesquisa já estabelecida. Tampouco em apontar para a lacuna do conhecimento a ser preenchida ou, ainda, anunciar os principais resultados encontrados. Ademais, não parece ser de praxe evidenciar interesse profissional no assunto pesquisado.

Tais resultados apontam para a singularidade característica das Humanidades, qual seja, o fato de não ter necessariamente um objeto material de análise, mas sim, aspectos subjetivos atrelados ao próprio comportamento ou ação humana, tais como valores, representações, sentimentos ou processos históricos e sociais - o que, amiúde, requer um tempo de observação e análise muito mais alargado, em comparação às demais áreas do saber, o que talvez justificaria a pouca ênfase dada a resultados práticos e imediatos.

Passemos agora para a análise da Tabela 2 abaixo, correspondente aos artigos produzidos pelos alunos das Ciências da Natureza e Matemática: 
Tabela 2 - Configuração dos movimentos e suas estratégias nos artigos da área de Ciências da Natureza e Matemática

\begin{tabular}{|c|c|c|c|c|c|c|c|c|}
\hline \multicolumn{2}{|c|}{ Artigos } & \multirow[t]{2}{*}{$M A$} & \multirow[t]{2}{*}{$M A$} & \multirow[t]{2}{*}{$B I O$} & \multirow[t]{2}{*}{$Q U$} & \multirow[t]{2}{*}{$Q U$} & \multirow[t]{2}{*}{$Q U$} & \multirow[t]{2}{*}{ Total } \\
\hline Movimentos & Estratégias & & & & & & & \\
\hline \multirow{12}{*}{$M 1$} & $E 1$ & & & & & $\mathrm{X}$ & $x$ & 2 \\
\hline & E2 & $x$ & $x$ & $x$ & & & & 3 \\
\hline & E3 & $x$ & $X$ & & & & & 2 \\
\hline & E4 & $x$ & $X$ & $X$ & $x$ & $x$ & $x$ & 6 \\
\hline & E5 & & & & & & & 0 \\
\hline & E6 & & & & & & & 0 \\
\hline & E7 & $x$ & & $x$ & & $x$ & & 3 \\
\hline & E8 & $x$ & $x$ & & & $x$ & $x$ & 4 \\
\hline & E9 & & & $\mathrm{X}$ & $x$ & $\mathrm{X}$ & & 3 \\
\hline & E10 & $X$ & $\mathrm{X}$ & & & $\mathrm{X}$ & $X$ & 4 \\
\hline & E11 & & & & & & & 0 \\
\hline & E12 & $x$ & & $x$ & $x$ & & & 3 \\
\hline \multirow{6}{*}{$M 2$} & E1 & $X$ & & & $X$ & & & 2 \\
\hline & E2 & & & & & & & 0 \\
\hline & E3 & $X$ & $X$ & $X$ & & & $X$ & 4 \\
\hline & $E 4$ & & & & $x$ & & $x$ & 2 \\
\hline & $E 5$ & & $x$ & & & & & 1 \\
\hline & $E 6$ & & & & & & & 0 \\
\hline \multirow{4}{*}{ M3 } & E1 & $X$ & & & & $x$ & & 2 \\
\hline & $E 2$ & $x$ & & & & $x$ & & 2 \\
\hline & E3 & $x$ & & & $x$ & $\mathrm{X}$ & & 3 \\
\hline & $E 4$ & & & & & & & 0 \\
\hline & $E 1$ & & & & & & & 0 \\
\hline & $E 2$ & & & & & $x$ & & 1 \\
\hline
\end{tabular}




\begin{tabular}{|c|c|c|c|c|c|c|c|c|}
\hline \multirow[t]{4}{*}{ M4 } & E3 & & & & & $X$ & & 1 \\
\hline & $E 4$ & & & & & $X$ & & 1 \\
\hline & $E 5$ & & & & & & & 0 \\
\hline & E6 & & & & $X$ & & & 1 \\
\hline \multirow{7}{*}{ M5 } & $E 1$ & & & $X$ & $X$ & $X$ & & 3 \\
\hline & $E 2$ & & & & & & & 0 \\
\hline & E3 & & & & & $X$ & & 1 \\
\hline & $E 4$ & $X$ & $X$ & $X$ & $X$ & $X$ & & 5 \\
\hline & $E 5$ & & & & & & & 0 \\
\hline & E6 & & & & & & & 0 \\
\hline & E7 & & & & & & $X$ & 1 \\
\hline
\end{tabular}

Com base na análise dos dados apresentados acima, pudemos perceber certa prevalência dos movimentos Introdução e Conclusão, respectivamente, o que aponta tanto para a preocupação por parte da área e dos seus pesquisadores com a revisão dos itens de pesquisa prévia sobre o tema, a indicação de lacunas ainda a preencher no conhecimento estabelecido e a tentativa de preencher esta lacuna no conhecimento, bastante semelhante ao modelo CARS (Creating a Research Space) proposto por Swales (1990, p.141), como também para a avaliação das contribuições e implicações teóricas para a área, isto é, para os impactos da pesquisa e como transformar seus resultados em ação.

Nessa direção, cumpre destacar duas estratégias diferentes das possibilidades apontadas por Motta-Roth e Hendges (2010) utilizadas pelos pesquisadores deste campo disciplinar. Trata-se do levantamento da biografia e das titulações do autor da teoria adotada, provavelmente para fins de validação da abordagem teórica escolhida, bem como a indicação do cronograma de aplicação das atividades da pesquisa no corpo do artigo e o uso de anexos com fotos das atividades realizadas durante o processo de obtenção dos dados - o que poderia suscitar certa tendência em valorizar a prática de evidenciar o trabalho desenvolvido pelo pesquisador, intervindo assim na realidade.

No que tange às estratégias não adotadas com frequência pelos pesquisadores da área de Ciências da Natureza e Matemática, nota-se uma semelhança com a área de Humanidades em relação aos movimentos Introdução e Conclusão. Quanto ao segundo e terceiro movimentos, percebe-se a ausência das práticas de tecer generalizações e descrever a análise de dados. A respeito do quarto movimento, verifica-se a ausência das estratégias de recapitular informação metodológica e comparar a descoberta com a literatura.

Em síntese, vale ressaltar que a estratégia retórica mais expressiva e recorrente nos 
artigos analisados das áreas de Humanidades e Ciências da Natureza e Matemática é a "citação de pesquisas prévias", o que aponta para a necessidade dos discentes em buscarem o respaldo de outros estudos relacionados com o tema investigado para desenvolverem suas próprias pesquisas.

No que se refere às demais estratégias, parece haver mais divergência do que convergência entre as duas áreas analisadas. Ao passo que a área de Ciências Humanas demonstra preocupação em valorizar a explicação dos objetivos, justificativa, relevância e escopo geral do trabalho desenvolvido, apontando para generalizações acerca dos resultados encontrados; as Ciências da Natureza e Matemática valorizam a avaliação das principais contribuições e implicações teóricas dos resultados encontrados para a área, bem como os impactos da pesquisa e a aplicação dos seus resultados na realidade social.

Comparando os resultados obtidos acima em ambas as áreas do saber, ratificamos que diferentes áreas do conhecimento possuem culturas disciplinares distintas. Em razão disso, as manifestações e/ou estratégias linguísticas de cada área revelam-se distintas entre si quanto aos objetivos, nomenclaturas, convenções, perfis e comportamentos sociais, demandas, normas e relações de poder. Daí também porque a interface teórica entre as vertentes sistêmico-funcional de Halliday e sociorretórica de Swales - devidamente alinhavadas por Motta-Roth e Hendges (2010) - se mostra bastante produtiva para a produção e análise de gêneros acadêmicos: ao passo que aquela concebe a linguagem como um conjunto de escolhas feitas em domínios particulares, esta investiga a relação inerente do gênero com cada situação específica - apontando, assim, para a relação intrínseca entre a organização do texto e a configuração do contexto.

\section{Apontamentos finais}

Ao discutirmos a potencialidade da abordagem sistêmico-funcional para se pensar a escrita no meio acadêmico, ressaltamos que colocar a língua em ação, por meio da escrita, nessa esfera de comunicação, é um processo complexo que vai se construindo por um movimento de escolhas semióticas para atender aos propósitos comunicativos do escritor. As escolhas realizadas em decorrência das funções da linguagem irão marcar o registro do texto, portanto, o registro possibilitará instanciar o gênero. É nesse sentido que percebemos como os movimentos de escolhas refletem o registro do gênero artigo acadêmico em áreas distintas do conhecimento.

As contribuições da abordagem sistêmico-funcional para pensar os aspectos da escrita no ensino superior apontam para o fato de que é elementar estudar as relações entre texto e contexto, as práticas sociais e discursivas para realizar escolhas semióticas adequadas. A análise dos gêneros, nas palavras de Eggins (2004), é o primeiro passo para explicitar a base social e cultural da linguagem. A Linguística Sistêmico-Funcional, por ser um conjunto de 
possibilidades teóricas e metodológicas, fornece um inventário para que se analisem as diversas práticas de linguagem e os diversos sentidos criados nos contextos e práticas sociais.

Sinalizamos que as discussões tecidas no decorrer deste texto tiveram o intuito de situar as possibilidades que a Linguística Sistêmico-Funcional apresenta para se pensar a funcionalidade da linguagem em uso em uma esfera de comunicação, ao descrever e ampliar o sistema de escolhas linguísticas possíveis para o atingimento dos propósitos comunicativos de diferentes culturas disciplinares. Trata-se de um conjunto de possibilidades, excluindo qualquer ideia em torno de certo ou errado, completa ou incompleta, para se pensar a complexidade de fenômenos ligados ao uso da linguagem no âmbito acadêmico.

\section{Referências}

BAKHTIN, M. Os gêneros do discurso. In: BAHKTIN, M. Estética da criação verbal. São Paulo: Martins Fontes, 1992. p. 277-236.

BARBARA, L; MOYANO, E. Textos e Linguagem Acadêmica: explorações sistêmico-funcionais em espanhol e português. Campinas, SP: Mercado das Letras, 2011.

BAZERMAN, C. Emerging perspectives on the many dimensions of scientific discourse. In: MARTIN, J. R.; VEEL, R. Reading science - Critical and functional perspectives on discourse of science. London/New York: Routledge, 1998.

BHATIA, V. K. Generic integrity in professional discourse. In: GUNNARSSON, B. L.; LINELL, P.; NORDBERG, B. (Orgs.). Text and Talk in Professional Contexts. ASLA: sskriftsrie 6, Uppsala, Sweden, 1994.

BATHIA, V. K. World of written discourse: a genre-based view. London/New York: Continuum, 2004.

BIASI-RODRIGUES, B. Aspectos cognitivos e retóricos da produção de resumos. In: CABRAL, L. G.; MORAIS, J. (Orgs.). Investigando a linguagem. Florianópolis: Mulheres, 1999a. p. 245-258.

BIASI-RODRIGUES, B. A escrita de resumos acadêmicos: evidências de uma realidade. In: MOURA, D. (Org.). Os múltiplos usos da língua. Maceió: EDUFAL. 1999b. p. 205-209.

BIASI-RODRIGUES, B. O processo de referenciação em gêneros acadêmicos. In: SBPC, 53, Salvador. Anais... Salvador: UFBA.

CARVALHO, F.F. Padrões de organização textual e lexicogramatical do gênero acadêmico resumo de tese: um estudo de caso. Trab. Ling. Aplic., Campinas, v.49, n.1, p. 115-128, jan./jul. 2010. Disponível em: <http://dx.doi.org/10.1590/S0103-18132010000100009> Acesso em: 14 fev. 2019. https://doi.org/10.1590/S0103-18132010000100009

CHRISTIE, F. Classroom discourse analysis: a functional perspective. London/New York: Continuum, 2002.

CHRISTIE, F. Systemic functional linguistics and a theory of language in education. Ilha do Desterro. Florianopolis n. 46, p.013-040, jan./jun. 2004.

EGGINS, S. An introduction to Systemic Functional Linguistics. 2.ed. London/New York: 
Continuum, 1994.

GROSSMANN, F. Por que e como as coisas mudam? Padronização e variação no campo do discurso científico. In: RINCK, F.; BOCK, F.; ASSIS, J. A. (Org.). Letramento e Formação Universitária. Campinas, SP: Mercado das Letras, 2015.

HALLIDAY, M. A. K.; MATTHIESSEN, C. An introduction to functional grammar. 3. ed. London: Hodder Education, 2004.

HALLIDAY, M. A. K.; HASAN, R. (Ed.). Language, context and text: aspects of language in a socialsemiotic perspective. 2ed. Oxford: OUP, 1985[1989; 2002].

HALLIDAY, M. A. K.; HASAN, R. Cohesion in english. London: Longman, 1976.

HALLIDAY, M. A. K. Language as social semiotic. London: Edward Arnold, 1978.

HALLIDAY, M. A. K. An introduction to functional grammar. London: Edward Arnold, 1985.

HYLAND, K. Disciplinary identities: Individuality and community in academic discourse. New York/Cambridge: Cambridge University Press, 2012.

KRESS, G.; VAN LEEUWEN, T. Reading images: the grammar of visual design. London/New York: Routledge, 1996[2006].

KRESS, G. Multimodality: A social semiotic approach to contemporary communication. London/New York: Routledge, 2010. https://doi.org/10.4324/9780203970034

MARINHO, M. A escrita nas práticas de letramento acadêmico. Revista Brasileira de Linguística Aplicada, Belo Horizonte, v.10, p.363-386, 2010. https://doi.org/10.1590/S1984$\underline{63982010000200005}$

MARTIN, J. R. Process and Text: Two Aspects of Human Semiosis. In: BENSON, J. D.; GREAVES, W. S. (orgs). Systemic Perspectives on Discourse - vol 1. Norwood: Ablex, 1985.

MARTIN, J.R. English text: system and structure. Philadelphia/Amesterdam: John Benjamins, 1992. https://doi.org/10.1075/z.59

MARTIN, J.R. Discourse of science: recontextualization, genesis, intertextuality and hegemony. In MARTIN, J. R; VEEL, R. Reading science - Critical and functional perspectives on discourse of science. London: Routledge, 1998.

MARTIN, J. R. Close Reading: Functional linguistics as a Tool for Critical Discourse Analysis. In: UNSWORTH, L. (Org.). Researching Language in schools and communities. London: Cassel, 2000. p. 275-302.

MARTIN, J. R.; ROSE, D. Working with Discourse: Meaning beyond the Clause. London/New York: Continuum, 2003[2007].

MARTIN, J. R.; ROSE, D. Genre relations - Mapping culture. London: Equinox, 2008.

MENDES, W. V. A perspectiva sistêmico-complexa na relação aos estudos da linguagem: experiências com textos acadêmicos. Diálogos das Letras, Pau dos Ferros, v.7, n.1, p.21-40, jan./abril 2018. https://doi.org/10.22297/dl.v7i1.2966

MEURER, J. L. Genre as Diversity, and Rhetorical mode as Unity in language Use. Ilha do Desterro, Florianópolis: UFSC/NUSPPLE. p. 133-140, 2002.

MEURER, J. L. Role Prescriptions, Social Practices, and Social Strucures: a sociological Basis for 
the Contextualization of Analysis in SFG and CDA. In: YOUNG, L.; HARRISON, C. (orgs.). Analysing Social Change Through Systemic Functional Linguístics and Critical Discourse Analysis. London/New York: Continuum. p. 85-99, 2004.

MEURER, J. L.; BONINI, A.; MOTTA-ROTH, D. Gêneros: teorias, métodos, debates. 2. ed. São Paulo: Parábola Editorial, 2005.

MORRIS, J. E. Principles of scientific and technical writing. New York: McGraw- Hill, 1966 apud CROOKES, G. 1986. Towards a validated analysis of cientific text structure. Applied Linguistics, v.7, n.1, p.57-70. https://doi.org/10.1093/applin/7.1.57

MOTTA-ROTH, D.; HENDGES, G. R. Uma análise de gênero resumo acadêmico (abstracts) em economia, linguística e química. Revista do Centro de Artes e Letras, Santa Maria: UFSM, 18(12), p.53-90, 1996.

MOTTA-ROTH, D. Uma análise transdisciplinar do gênero "abstract". Intercâmbio, n. 7, p. 125134, 1998.

MOTTA-ROTH, D. Redação básica - Princípios básicos. Santa Maria: Labler - Laboratório de Pesquisa e ensino de Leitura e Redação, 2001.

MOTTA-ROTH, D. Questões de metodologia em análise de gêneros. In: KARWOSKI, A. M.; GAYDECZKA, B.; BRITO, K. S. (Org.). Gêneros textuais: reflexões e ensino. 2. ed. Rio de Janeiro: Lucerna, 2006a. p. 145-163.

MOTTA-ROTH, D. O ensino de produção textual com base em atividades sociais e gêneros textuais. Revista Linguagem em (Dis)curso, v. 6, n. 3, p. 495-517, set./dez. 2006b.

MOTTA-ROTH, D. Análise Crítica de Gêneros: contribuições para o ensino e a pesquisa de Linguagem. Revista Delta, v.2, n.24, p. 341-383, 2008. https://doi.org/10.1590/S0102$\underline{44502008000200007}$

MOTTA-ROTH, D. Escrevendo no Contexto: Contribuições da LSF para o ensino de redação acadêmica. Anais do 33rd International Systemic Functional Congress, São Paulo: PUC-SP p. 828-860, 2006.2 Disponível em: <http://www4.pucsp.br/isfc/proceedings/Artigos\%20pdf/40acd_mottaroth_828a860.pdf> Acesso em: 05 fev. 2019.

MOTTA-ROTH, D.; HENDGES, G. H. A produção textual na universidade. São Paulo: Parábola Editorial, 2010.

NOGUCHI, J. T. The science review article: an opportune genre in the construction of science. Tese de doutorado, Universidade de Birmingham, UK, 2001.

ROSE, D; J. R. Learning to write, reading to learn: genre, knowledge and pedagogy in the Sidney School. London: Equinox, 2012.

SELBACH, H. V.; MOTTA-ROTH, D.; SCHMIDT, A. P. C. Academic Literacies: Appraisal and social sanction about authorship and scientific integrity. Revista Brasileira de Linguística aplicada, $\mathrm{v}$. 18, n. 4, p. 703-736, 2018. Disponível em: <http://www.scielo.br/scielo.php?pid=S198463982018000400703\&script=sci_arttext> Acesso em: 06 fev. 2019. https://doi.org/10.1590/1984-6398201812991

SILVA, E. C. M. Gêneros na teoria sistêmico-funcional. Revista Delta, v. 1, n.34, p. 305-330, 2018. Disponível em: <http://www.scielo.br/pdf/delta/v34n1/1678-460X-delta-34-01-305.pdf> 
Acesso em: 06 fev. 2019. https://doi.org/10.1590/0102-4450297878862629695

SWALES, J. M. Genre Analysis: English in academic and research settings. Cambridge: Cambridge University Press, 1990.

SWALES, J. M. Research genre: exploration and applications. New York: Cambridge University Press, 2004. https://doi.org/10.1017/CB09781139524827

THOMPSON, G. Introducing Functional Grammar. 2.ed. Oxford: Oxford University Press, 2003. VIAN JUNIOR, O.; LIMA-LOPES, R. A perspective teleológica de Martin para a análise dos gêneros textuais. In: MEURER, J. L.; BONINI, A.; MOTTA-ROTH, D. (Org.). Gêneros, teorias, métodos, debates. São Paulo: Parábola Editorial, 2005.

VIAN JR., O. O artigo na família de gêneros acadêmicos: notas sobre aspectos tipológicos, topológicos e seu papel no ensino-aprendizagem de leitura. In: BARBARA, L; MOYANO (Org.). Textos e Linguagem acadêmica: explorações sistêmico-funcionais em espanhol e português. Campinas, SP: Mercado das Letras, 2011.

VIAN JR, O. Gêneros discursivos e conhecimento sobre gêneros no planejamento de um curso de português instrumental para Ciências Contábeis. Linguagem em (Dis)curso: 18 fev. 2018.

Recebido em: 22/02/2019

Aceito em: 26/05/2019 